\title{
Erythrodermic Lymphomatoid Granulomatosis: A Case Report
}

\author{
Kaoru Imaoka ${ }^{a}$ Minao Furumura $^{a}$ Riruke Maruyama $^{b}$ \\ Ren Nagasako ${ }^{c}$ Eishin Morita ${ }^{a}$ \\ Departments of ${ }^{a}$ Dermatology and ${ }^{b}$ Pathology, Shimane University Faculty of \\ Medicine, Izumo, and ' Department of Clinical Laboratory, Osaka-fu Saiseikai \\ Tondabayashi Hospital, Tondabayashi, Japan
}

\section{Key Words}

Lymphomatoid granulomatosis · Erythrodermia · Pulmonary infiltrations

\begin{abstract}
A 70-year-old man was admitted to our hospital for evaluation of a rapidly progressive erythrodermia. He had superficial lymph node swelling and gluteal/inguinal nodosum-like lesions. A skin biopsy of the erythrodermia showed dense mixed infiltrates distributed throughout the whole dermis, predominantly consisting of small lymphocytes and histiocytes with multinucleated giant cells presenting with a granulomatous appearance. The dense infiltrates showed a characteristic angiocentric pattern surrounding the upward vasculature interconnecting the subcutaneous/subpapillary plexus in the dermis. Some infiltrating lymphocytes showed mild atypia with somewhat irregularly shaped nuclei. Their immunologic staining profiles supported the diagnosis of lymphomatoid granulomatosis. Despite the dense angiocentric infiltration in the dermis, typical angiodestructive infiltration with necrotic changes was not seen on pathological examination. In this case, in situ hybridization yielded negative findings for Epstein-Barr virus-encoded RNAs. Three months after the onset of erythrodermia, the patient developed pulmonary lymphomatoid granulomatosis. Corticosteroid pulse therapy was effective for the treatment of severe pulmonary infiltrations and erythrodermia. However, there had been mild recurrence of the condition or hypereosinophilia during the 4 years of follow-up. Low maintenance doses of cyclophosphamide and corticosteroid provided the patient symptomatic relief to date.
\end{abstract}

\section{Introduction}

Lymphomatoid granulomatosis (LYG) is a rare Epstein-Barr virus (EBV)-associated B-cell lymphoproliferative disorder that has similar characteristics as lymphomatous and granulomatous diseases. The disease is pathologically classified as a large angiocentric and angiodestructive B-cell lymphoma that consists of small numbers of 
EBV-positive neoplastic B-cells, along with a diffuse background predominantly expressing reactive $\mathrm{CD}^{+}$and/or $\mathrm{CD} 4^{+}{ }^{+}$-cells.

The lungs, liver, kidneys, and nervous system are affected most frequently. Usually, the skin is affected in approximately $45 \%$ of the patients [1]. Isolated cutaneous LYG has also been reported [2]. Patchy, occasionally painful erythematous macules, papules, and plaques are typically observed in the gluteal regions and in the extremities. Erythema may sometimes involve nodosum-like subcutaneous nodules that tend to ulcerate but are often limited to the trunk [3]. In this paper, we report a rare case of erythema that initially presented with erythrodermic skin lesions and progressed to pulmonary symptoms.

\section{Case Report}

A 70-year-old Japanese man presented with a progressively worsening cutaneous papuloerythematous rash on the trunk. During the initial assessment, laboratory investigations showed only hypereosinophilia in the peripheral blood without atypical lymphocytes. The initial skin biopsy revealed moderate infiltration of lymphocytes and eosinophils in the surrounding vessels of the superficial dermis. Because he had received indapamide (a sulfonamide-derived diuretic), doxazosin mesylate for hypertension, and other medications for benign prostate hypertrophy 1 year before the onset of the condition, drug eruption was suspected, and all his medicines were suspended. He was treated with topical corticosteroids. Despite the topical treatment, the papules rapidly spread to his entire body. He had recurring high fever and, therefore, was admitted to our hospital. No human T-cell leukemia virus type 1 or human immunodeficiency virus antibodies were detected in the serum. The serum levels of antibodies against the EBV-specific antigens were as follows: anti-viral capsid antigen (VCA):immunoglobulin G (IgG), 1:40; VCA:IgM, negative; VCA:IgA, negative; early antigen:IgG, negative; early antigen:IgA, negative; and EBV-determined nuclear antigen:IgG, 1:10. His whole-body CT scan showed no lymph node swellings in the neck and the thoracic and abdominal cavities.

The second skin biopsy showed superficial and deep dense mixed infiltrates in the dermis without epidermal involvement. The infiltrates were angiocentric, and they predominantly consisted of small lymphocytes and histiocytes with multinucleated giant cells. The infiltrating lymphocytes sometimes showed mild atypia with slightly irregularly shaped nuclei. Their profiles were $\mathrm{CD} 3^{+} / \mathrm{CD}^{+} / \mathrm{CD}^{+} /$ CD45R0 + /CD4- (fig. 1). The histiocytes were CD68 ${ }^{+}$. The CD20+/CD79a ${ }^{+}$B-cells were few. Although angiodestruction and necrosis were absent, cellular infiltration vaguely showed a granulomatous appearance. In situ hybridization yielded negative findings for EBV-encoded RNAs.

Although topical corticosteroid therapy was further continued, his cutaneous lesions continued to spread on to nearly his whole body. Two months after the onset, the lesions merged and took an erythrodermic appearance, with superficial lymph node swelling (fig. 2). Several nodular skin lesions were also observed in the inguinal and perineal areas. The third skin biopsy revealed a large number of infiltrating lymphocytes, whereas no necrosis or large lymphocytes were seen (ig. 3 ). The Ig heavy-chain or T-cell receptor beta-chain rearrangements in the skin were not detected in PCR and southern blot analyses.

Three months after the onset of the condition, the patient had sustained high fever and cyanosis. However, he did not have cough or chest pain. His chest CT scan showed diffuse infiltrative lesions in the bilateral lungs and pleural effusion without nodules or lymph node swelling. Of the cells in the pleural effusion, $96.9 \%$ were small lymphocytes and histiocytes. The cytodiagnosis was negative for malignancy. His arterial blood gas examination revealed severe hypoxemia $\left(\mathrm{PO}_{2} 29.9 \mathrm{~mm} \mathrm{Hg} ; \mathrm{PCO}_{2}\right.$ $37.4 \mathrm{~mm} \mathrm{Hg} ; \mathrm{pH}$ 7.462, A-aDo2 79.1). Although a lung biopsy was not done because of severe hypoxemia, LYG was diagnosed on the basis of the cutaneous pathological findings and the pulmonary symptoms. He was treated with corticosteroid pulse therapy (methylprednisolone $1 \mathrm{~g} /$ day for 3 days) for acute respiratory distress syndrome. The steroid pulse therapy was quite effective. Soon after, his hypoxemia improved and the diffuse reticular shadows of the lungs disappeared on the third day of the pulse therapy. Furthermore, the erythrodermia and the hypereosinophilia improved with the intravenous corticosteroid therapy. 
In the course of the corticosteroid dosage tapering, mild hot flashes on his face, trunk, and arms occasionally appeared, and gradually, the number of eosinophils increased. Although cyclophosphamide $(50 \mathrm{mg} /$ day) was taken with prednisolone $(12 \mathrm{mg} /$ day), mild recurrence with several small nodular lesions in the perineal areas without erythrodermia was observed 7 months after the onset of the condition. However, the lesions disappeared gradually with the sustained therapy, and the patient has been continuously been taking prednisolone at a dose of $11 \mathrm{mg} / \mathrm{day}$ and cyclophosphamide at a dose of $50 \mathrm{mg}$ every other day, without recurrence, for 4 years up to date.

\section{Discussion}

LYG was first described by Leibow et al. [1] in 1972 and was initially thought to be a $\mathrm{T}$-cell lymphoproliferative disorder owing to the prominence of $\mathrm{CD}^{+} \mathrm{T}$-cells observed in biopsy specimens. It was later demonstrated that LYG is an EBV-associated B-cell lymphoproliferative disorder, in which a large number of infiltrating T-cells are reactive [4-6].

EBV is usually detected in LYG because of the type 3 latency pattern. Therefore, currently LYG is considered as an EBV-related T-cell-rich monoclonal B-cell lymphoproliferative disorder with a broad pathological spectrum and variable malignant potential. Angiocentric infiltration with vasculitis and necrosis is pathognomonic and results from the angiodestructive potential of the polymorphous lymphoid infiltrate, with predominantly reactive T-lymphocytes and sparse clonal EBVpositive B-cells.

The dermatologic manifestations of LYG are diverse. However, most patients show multiple erythematous, dermal, and subcutaneous papules and nodules on the extremities and/or on the trunk $[3,5]$. The histologic appearance of the cutaneous lesions correlates with the clinical pattern. Angiodestruction, necrosis, and cellular atypia are much more common in the deeper subcutaneous nodules. Lipford et al. [7] divided LYG lesions into 3 histologic grades on the basis of the degree of cytologic atypia in the lymphoid cells and the extent of the inflammatory background. Grade I lesions consist of an angiocentric and angiodestructive lymphoid proliferation without cytologic atypia. Necrosis is not usually observed. Grade II lesions contain occasional large lymphoid cells with few marked cytologic atypia. Necrosis is more commonly seen. Grade III lesions show marked cytologic atypia present in small and large lymphoid cells, which is termed angiocentric lymphomas. Necrosis is prominent. Previous studies [5, 6] have shown that the number of EBV-positive cells correlates with histologic grade. Beaty et al. [5] revealed that the plaque lesions were negative for EBV and demonstrated IgH polyclonal patterns. The EBV-positive lesions contained large cytologically atypical cells and were associated with marked necrosis. Our case predominantly presented erythematous plaque lesions that resulted in erythrodermia and a negative reaction to EBV. According to the histologic grading described above, our case was grade I, which corresponded to the results of the in situ hybridization for EBV and the PCR assay for the IgH gene.

LYG is a lymphoproliferative disorder primarily involving the lungs. Cutaneous lesions appear before the onset of the pulmonary disorder in 15\% of LYG cases, such as in our case [5]. Pulmonary lesions in LYG present a variety of radiographic features, from diffuse infiltrates to nodules, as well as the presence of cutaneous lesions $[3,6]$. Although there were no pulmonary nodular lesions, our case showed severe hypoxemia 
due to diffuse infiltrates. A similar case of LYG mimicking interstitial pneumonia without cutaneous lesions was reported to be histological grade I and negative for EBV [8].

The immunophenotypes of the infiltrating lymphocytes in LYG previously reported are $\mathrm{CD}^{+}, \mathrm{CD}^{+/-}, \mathrm{CD}^{+}, \mathrm{CD} 20^{+}$, and $\mathrm{CD}_{79 a^{+}}[2,5-7,9]$. In LYG, EBV is localized to CD20+ B-cells in the lungs and the skin $[4,10,11]$. Several reports indicate that EBV was more difficult to identify in skin lesions than in the lungs in LYG [4, 5]. McNiff et al. [4] postulated that EBV-containing B-cells are few or EBV-containing B-cells did not consistently home to skin, which is the reason for the difficulty in detecting LYG in the skin [4]. The immunohistochemical stainings of the cutaneous lesions in our case showed a few B-cells in the skin, which might show false-negative results for EBV. In addition, serological analysis revealed only the past infection, without reactivation of EBV.

The mechanism by which the condition of the present case progressed to erythrodermia is unclear. Most erythrodermic cases of lymphoproliferative disorders present characteristic pathological features. However, it is often observed that the number of atypical cells differ greatly from specimen to specimen in the same patient. Abel et al. [12] found that the lymphocyte phenotypes of their patients with erythrodermia caused by mycosis fungoides/Sezary syndrome or benign disease were strikingly similar. They suggested that erythrodermic mycosis fungoides/Sezary syndrome skin lesions compromise a greater proportion of cells involved with host response than other types of mycosis fungoides. It is very likely that numerous host response T-cells lead to symptoms of erythrodermia.

Macon et al. [13] revealed that the presence of interleukin (IL)-4 in T-cell-rich B-cell lymphomas (TCRBCLs) but not in other diffuse large B-cell lymphomas and reactive lymph nodes indicated that IL-4 may be a major factor involved in the pathobiology of TCRBCLs. In addition, several interesting studies $[14,15]$ suggested that IL-4 not only have proliferative effects on resting B-cells but also anti-proliferative effects on activated neoplastic B-cells. IL-4 may influence the pronounced T-cell reaction in the TCRBCLs and contribute to the low numbers of neoplastic B-cells. We speculate that some cytokines like IL-4 may cause host response by abundant production of T-cells, suppress proliferation of neoplastic B-cells, and advance skin lesions to erythrodermic features.

A number of studies trying to find an effective way to treat LYG have been reported. However, a standard therapy has not yet been established, and treating LYG remains a challenge. The variety of symptoms and the clinical course make this condition difficult to diagnose and treat. Grading the disease by immunohistological examination and in situ hybridization is an important basis for choosing the right treatment that is currently available. Initial use of combination chemotherapy, such as CHOP, was recommended for all aggressive cases that could develop to malignant lymphoma. Interferon- $\alpha$ has been a promising therapy because LYG grades I and II without monoclonal B-cell population is not an autonomous malignant proliferation but rather an EBV-driven lymphoproliferative disorder [5]. However, in the present case, which was categorized as grade I and showed erythrodermia without B-cell monoclonality, the low maintenance doses of corticosteroid and cyclophosphamide were adequate to suppress the abundant activated T-cells and sustain clinical remission for a long period. 


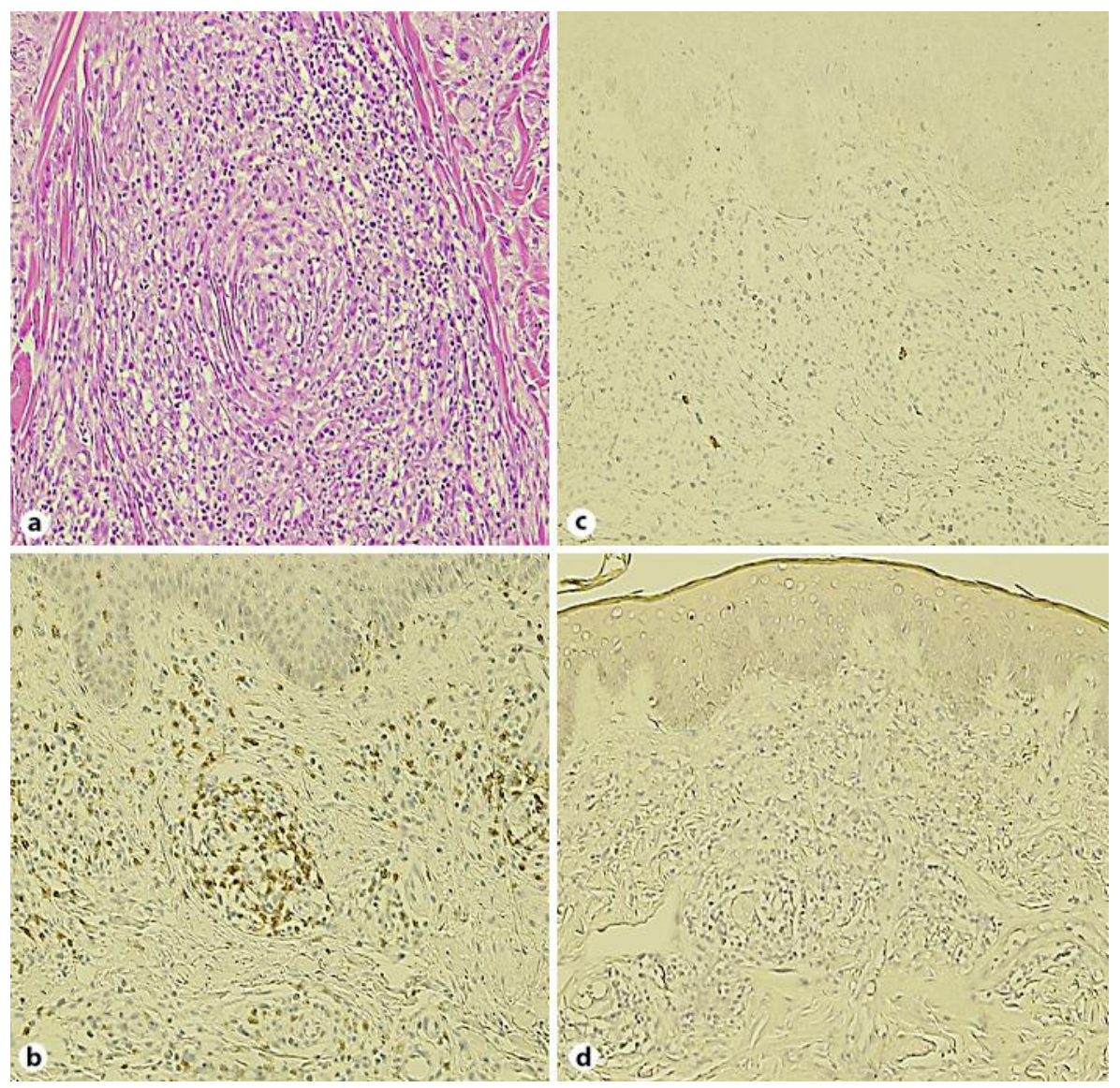

Fig. 1. Second skin biopsy specimen. a Hematoxylin-eosin stain of the upper dermis of the erythrodermic skin, demonstrating dense infiltrates of small atypical lymphocytes, eosinophils, histiocytes, and multinuclear giant cells around vessels, with an angiocentric pattern and skin appendages (original magnification $\times 100$ ). Granulomatous changes are also seen.

b Immunohistochemical staining of CD $8^{+} \mathrm{T}$-cells around small vessels in the upper dermis (original magnification $\times 40$ ). $\mathbf{c ~ C D} 20^{+}$B-cells sparsely located in the lesion. $d$ In situ hybridization showing a negative staining result for EBV-encoded small RNA (original magnification $\times 100$ ). 


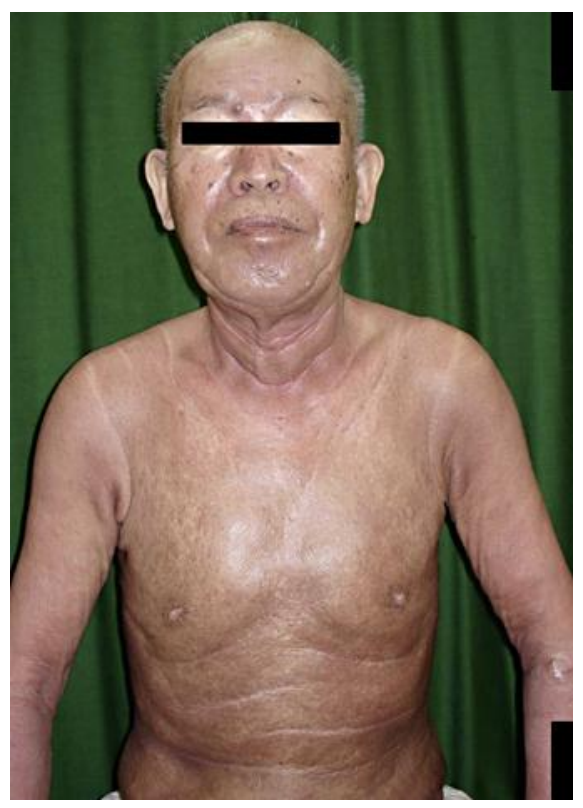

Fig. 2. The patient developed erythrodermic lesions covering the whole body. Erythematous papules are also seen in his upper extremities.

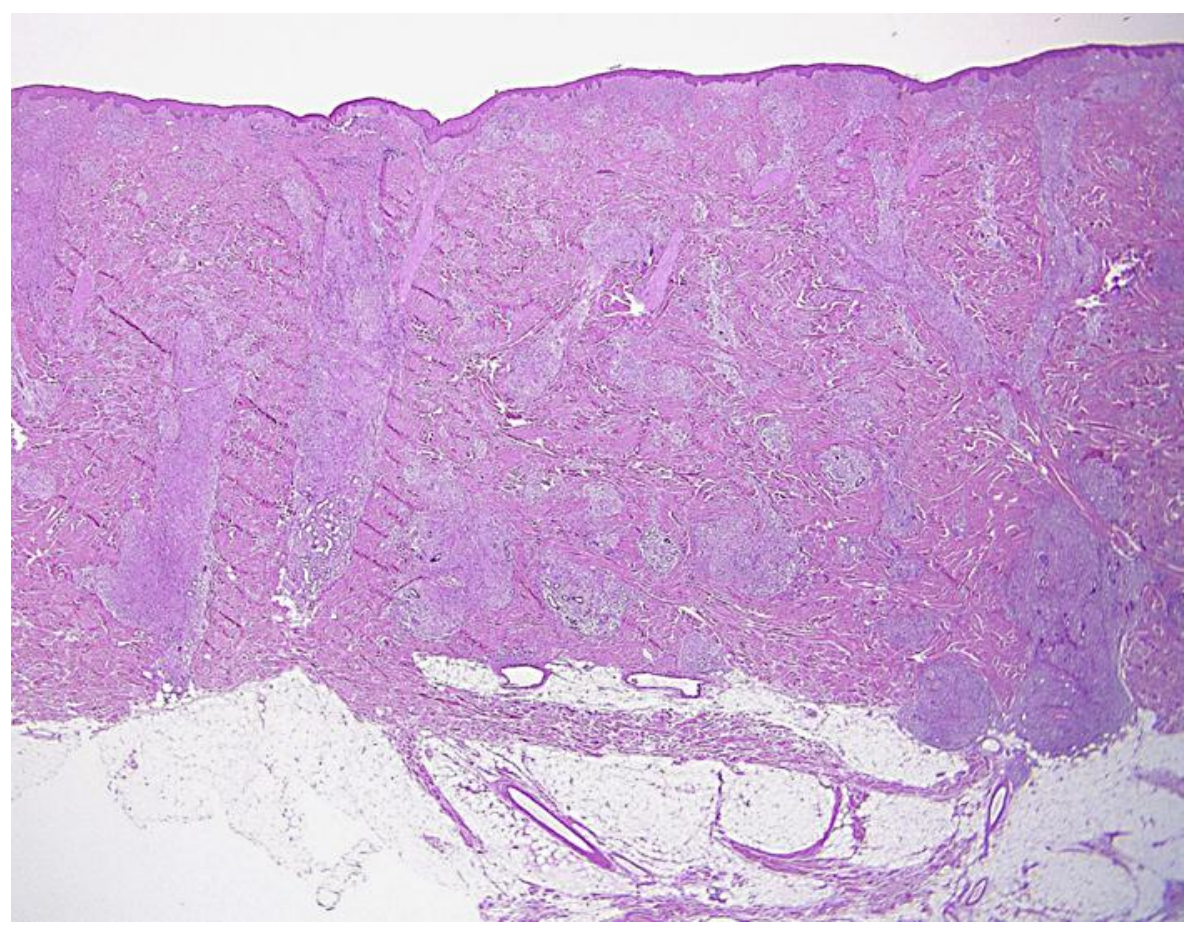

Fig. 3. Third skin biopsy specimen. Hematoxylin-eosin stain of the whole dermis of the indurated erythrodermic skin of the back. Dense lymphocyte infiltrates are seen in a characteristic columnar angiocentric pattern, surrounding the upward vasculature interconnecting the subcutaneous/ subpapillary plexus (original magnification $\times 1.25$ ). 


\section{References}

1 Leibow AA, Carington CRB, Friedman PJ: Lymphomatoid granulomatosis. Hum Pathol 1972;3:457-558.

-2 Sebire NJ, Haseiden S, Malone M, Davies EG, Ramsay AD: Isolated EBV lymphoproliferative disease in a child with Wiskott-Aldrich syndrome manifesting as cutaneous lymphomatoid granulomatosis and responsive to anti-CD20 immunotherapy. J Clin Pathol 2003;58:555-557.

-3 James WD, Odom RB, Katzenstein AA: Cutaneous manifestation of lymphomatoid granulomatosis. Report of 44 cases and a review of the literature. Arch Dermatol 1981;117:196-202.

-4 McNiff JM, Cooper D, Howe G, Crotty PL, Tallini G, Crouch J, Esen RN: Lymphomatoid granulomatosis of the skin and lung : an angiocentric T-cell-rich B-cell lymphoproliferative disorder. Arch Dermatol 1996;132:1464-1470.

5 Beaty MW, Toro J, Sorbara L: Cutaneous lymphomatoid granulomatosis. Am J Surg Pathol 2001;25:1111-1120.

6 Guinee DG Jr, Perkins SL, Travis WD, Holden JA, Tripp SR, Koss MN: Proliferation and cellular phenotype in lymphomatoid granulomatosis: implications of a higher proliferation index in B cells. Am J Surg Pathol 1998;22:1093-1100.

7 Lipford EH, Margolick JB, Longo DL, Fauci AS, Jaffe ES: Angiocentric immunoproliferative lesions: a clinicopathologic spectrum of post-thymic T-cell proliferations. Blood 1988;72:1674-1681.

-8 Ishii H, Kishi K, Kushima H, Hashinaga K, Umeki K, Ohama M, Tokimatsu I, Hiramatsu K, Kadota J: Pulmonary lymphomatoid granulomatosis radiologically mimicking inters titial pneumonia. Nihon Kokyuki Gakkai Zasshi 2007;45:483-488.

-9 Yazdi AS, Metzler G, Weyrauch S, Berneburg M, Bitzer M, Müller-Hermelink HK, Röcken M: Lymphomatoid granulomatosis induced by imatinib-treatment. Arch Dermatol 2007;143:1222-1223.

-10 Guinee DG Jr, Jaffe E, Kingma D, Fishback N, Wallberg K, Krishnan J, Fizzera G, Travis W, Koss M: Pulmonary lymphomatoid granulomatosis. Evidence for a proliferation of Epstein-Barr virus infected B-lymphocytes with a prominent T-cell component and vasculitis. Am J Surg Pathol 1994;18:753-764.

-11 Myers JL, Kurtin PJ, Katzenstein AA, Tazelaar HD, Colby TV, Strickler JG, Lloyd RV, Isaacson PG: Lymphomatoid granulomatosis. Evidence of immunophenotypic diversity and relationship to EpsteinBarr virus infection. Am J Surg Pathol 1995;19:1300-1312.

-12 Abel EA, Lindae ML, Hoppe RT, Wood GS: Benign and malignant forms of erythroderma: cutaneous immunophenotypic characteristics. J Am Acad Dermatol 1988;19:1089-1095.

-13 Macon WR, Cousar JB, Waldron JA Jr, Hsu SM: Interleukin-4 may contribute to the abundant T-cell reaction and paucity of neoplastic B cells in T-cell-rich B-cell lymphomas. Am J Pathol 1992;141:10311036.

14 Defrance T, Fluckiger AC, Rossi JF, Magaud JP, Sotto JJ, Banchereau J: Antiproliferative effects of interleukin-4 on freshly isolated non-Hodgkin malignant B-lymphoma cells. Blood 1992;79:990-996.

15 Taylor CW, Grogan TM, Salmon SE: Effects of interleukin-4 on the in vitro growth of human lymphoid and plasma cell neoplasms. Blood 1990;75:1114-1118. 